\title{
Current approach to nocturnal hypertension
}

\author{
Hüsnü Değirmenci*, Eftal M Bakırcı and Hikmet Hamur \\ Department of Cardiology, Faculty of Medicine, Erzincan Binali Yildırım University, Turkey
}

\begin{abstract}
Nocturnal hypertension is an important risk factor for cardiovascular and cerebrovascular diseases. Increased sympathetic activity, increased renin angiotensin aldesteron activity and increased circulation volume are the mechanisms that lead to nocturnal hypertension. Nocturnal hypertension is defined as systolic blood pressure $>110 \mathrm{mmHg}$ and/or diastolic blood pressure $>65 \mathrm{mmHg}$ according to the American guideline. In the European guideline, nocturnal hypertension is defined as systolic blood pressure $120 \mathrm{mmHg}$ and / or diastolic blood pressure $70 \mathrm{mmHg}$. Lifestyle changes are important in treatment. In addition, diuretics, angiotensin converting enzyme inhibitors, angiotensin receptor blockers, calcium channel blockers, sacubitril valsartan and combinations of these drugs have an important place in the treatment. Taking these drugs at night is more effective than taking them in the morning in lowering nocturnal blood pressure.
\end{abstract}

\section{Introduction}

Nocturnal hypertension is an important risk factor for cardiovascular and cerebrovascular diseases [1]. With the widespread use of ambulatory blood pressure, the diagnosis of nocturnal hypertension has increased [1]. Nocturnal hypertension causes target organ damage. While there is not enough decrease in blood pressure at night compared to the daytime, it is called nondipping pattern, while the increase in nighttime blood pressure compared to daytime is called reverse dipping pattern [2]. Nocturnal hypertension is associated with these patterns.

Nondipping pattern is associated with myocardial infarction, heart failure, stroke, coronary events, and cardiovascular mortality [2]. The prognostic significance of the reverse dipping pattern is not clear. However, this pattern has been shown to be associated with adverse cardiovascular events [3]. Because of this importance, we have written this review called the current approach to nocturnal hypertension.

\section{Mechanisms of nocturnal hypertension}

Because salt sensitivity and sleeping in the supine position increase the circulation volume, it increases nighttime blood pressure. As vascular damage decreases baroreflex functions, it increases nighttime blood pressure [4].

Increase in night volume leads to kidney damage by increasing intraglomerular pressure [4]. In addition, this increase in volume leads to heart failure by increasing left ventricular prelode and wall stress.

Decreased baroreflex functions can trigger stroke, myocardial infarction, and vascular dementia. Diurnal hormonal changes affecting the autonomic nervous system, such as the sympathetic nervous system, parasympathetic nervous system, insulin, cortisol, and renin angiotensin aldesteron system, lead to circadian blood pressure changes [1].

Conditions such as increased activity of the renin angiotensin aldesterone system, increased sympathetic nervous system activity, sodium retention, obstructive sleep apnea syndrome, impaired renal function, age, obesity, diabetes, secondary hypertension, heart failure, decreased physical activity, insomnia and work stress cause nocturnal hypertension $[1,4]$.

\section{Definition of nocturnal hypertension}

According to the European guideline, ambulatory blood pressure monitoring is preferred over home blood pressure monitoring in the evaluation of nocturnal blood pressure and dipping pattern [5].

According to the American guideline, a systolic blood pressure $\geq 110 \mathrm{mmHg}$ and/or diastolic blood pressure $\geq 65 \mathrm{mmHg}$ is defined as nocturnal hypertension [6]. Isolated systolic hypertension definition is used in nocturnal hypertension patients with clinical and morning blood pressure $<130 / 80 \mathrm{mmHg}$. A clinical and morning home blood pressure of $<130 / 80 \mathrm{mmHg}$ is called masked nocturnal hypertension [6]. If this value is seen under medication, the term uncontrollable nocturnal hypertension is used.

In the European guideline, systolic blood pressure $\geq 120 \mathrm{mmHg}$ and/or diastolic blood pressure $\geq 70 \mathrm{mmHg}$ is defined as nocturnal hypertension [5]. There are 4 patterns of circadian blood pressure. These patterns are determined by the percentage change in nighttime blood pressure relative to daytime blood pressure. Excessive dipping, dipping, nondipping, inverse dipping/rising patterns are patterns of circadian blood pressure. If the decrease in blood pressure is $>20 \%$, it is mentioned excessive dipping, 11-20\% dipping, 1-10\% nondipping and $0 \%$ inverse pattern. However, an increase in nighttime blood pressure compared to daytime blood pressure is called reverse/rising pattern $[1,4]$.

Dipping pattern is not observed in conditions such as sleep disorder, obstructive sleep apnea, obesity, high salt intake, orthostatic hypotension, autonomic dysfunction, chronic kidney disease, diabetic nephropathy and advanced age [1].

*Correspondence to: Hüsnü Değirmenci, Department of Cardiology, Faculty of Medicine, Erzincan Binali Yıldırım University, Turkey, E-mail: husnudr1982@gmail.com

Key words: nocturnal hypertension, cardiovascular, cerebrovascular, mechanism, diagnosis, treatment

Received: November 09, 2020; Accepted: November 19, 2020; Published: November 30, 2020 


\section{Treatment}

Increased sympathetic nervous system activity, increased renin angiotensin aldesteron system activity and increased circulation volume are the mechanisms that lead to nocturnal hypertension.

Various treatment modalities such as salt restriction, diuretic, angiotensin converting enzyme inhibitor, angiotensin receptor blocker, combination of angiotensin converting enzyme with diuretic or combination of angiotensin converting enzyme inhibitors with calcium channel blockers can be used in the treatment of nocturnal hypertension. Aliskiren, a direct renin inhibitor, can be used in nocturnal hypertension. Calcium channel blockers can control blood pressure in patients with reverse dipping or excessive dipping patterns [1].

Let's evaluate the treatment algorithm according to the 2017 American guideline [6]. According to this guideline, the first target of treatment is morning hypertension. If the morning blood pressure is $<130 / 80 \mathrm{mmHg}$, the second goal is passed. Our second goal is uncontrollable nocturnal hypertension with a mask. Salt restriction, diuretic, mineralocorticoid receptor antagonist, sacubitril/valsartan, or sodium glucose cotransporter 2 inhibitors can be used to reduce the circulating volume for this goal. Calcium channel blockers can be used in vascular diseases. Sympatholytics, renal denervation or continuous positive airway pressure can be used in obstructive sleep apnea syndrome and sympathetic activity increase. If there is insomnia, melatonin, melatonin receptor antagonists, orexin receptor blockers can be used. A significant benefit of beta blockers in nocturnal hypertension has not been demonstrated.

In one study, taking the antihypertensive drug at night provided better blood pressure control than taking it in the morning. Cardiovascular disease risk has been found to be lower in antihypertensive drugs taken at night as combination therapy [1].

\section{References}

1. Tadic M, Cuspidi C, Grassi G, Mancia G (2020) Isolated Nocturnal Hypertension: What Do We Know and What Can We Do? Integr Blood Press Control 13: 63-69. [Crossref]

2. Palatini P, Verdecchia P, Beilin LJ, Eguchi K, Imai Y, et al. (2020) Association of extreme nocturnal dipping with cardiovascular events strongly depends on age. Hypertension 75: 324-330. [Crossref]

3. De la Sierra A, Gorostidi M, Banegas JR, Segura J, de la Cruz JJ, et al. (2014) Nocturnal hypertension or nondipping: which is better associated with the cardiovascular risk profile? Am J Hypertens 27: 680-687. [Crossref]

4. Kario K (2018) Nocturnal Hypertension. Hypertension 71: 997-1009.

5. Williams B, Mancia G, Spiering W, Rosei EA, Azizi M, et al. (2018) 2018 ESC/ESH Guidelines for the management of arterial hypertension. Eur Heart J 39: 3021-3104. [Crossref]

6. Carey RM, Calhoun DA, Bakris GL, Brook RD, Daugherty SL, et al. (2018) Resistan hypertension: detection, evaluation and management, A Scientific Statement from the American Heart Association. Hypertension 72: e53-e90. [Crossref]

Copyright: (C2020 Değirmenci H. This is an open-access article distributed under the terms of the Creative Commons Attribution License, which permits unrestricted use, distribution, and reproduction in any medium, provided the original author and source are credited. 